\title{
Turning Science Into Effective Policy Advocacy-The Foundations for the Evidence-Based Policymaking Act of 2018
}

\author{
Tom Kane
}

The mission of the Journal of Physical Activity and Health (JPAH) is to be the primary global outlet for information relevant to the science and practice of physical activity as it relates to health. To accomplish its mission, JPAH publishes peer-reviewed original research, practice reports, and systematic review papers for researchers and practitioners - the JPAH Community - whose work is impacted by physical activity. Although not explicitly referenced in the mission statement, the content published in the JPAH has another target audience-policymakers at all levels of government (local, state, federal, international, and multilateral) and in all 3 branches (executive/administrative, legislative, and judicial).

Much has been made in recent years about the use of science in the policymaking process. The importance of evidence-based policymaking at the US federal government level was recognized in 2016, when Congress passed the Evidence-Based Policymaking Commission Act of 2016. ${ }^{1}$ To better inform policymaking, the Commission was charged with examining methods for increasing the availability and use of data that could be used to evaluate the effectiveness of government programs. In its report issued in September 2017, the Commission defined evidence as aggregatelevel data produced by "statistical activities" with a "statistical purpose" that is potentially useful for evaluating government programs and policies and evidence-based policies as the application of evidence to inform decisions in government. ${ }^{2}$ As the Commission noted in the Report, "The American people want a government that solves problems. This requires that decision makers have good information to guide their choices about how current programs and policies are working and how they can be improved." Also, as the Commission wrote in the Report's Conclusion, "Without the use of evidence in our democracy, we are only guessing at whether government programs and policies are achieving their intended goals."

The principles of the Report and the Report's findings formed the basis of the Foundations For Evidence-Based Policymaking Act of 2018 ("Act"), H.R. 4174, which was signed into law on January 14, 2019. ${ }^{3}$ The Act enhances and strengthens evidencebuilding activities at the federal level, including the following: (1) establishing and embedding important evidence-based-related positions in the federal agencies, (2) establishing an architecture for policy development and coordination of information across the federal executive branch, and (3) establishing a framework and governing principles for the collection and use of data by the federal agencies (including the protection of confidential information).

Importantly, that Act provides several key opportunities for the public and nongovernmental experts (ie, scientists and

Kane (psychepitjk@ gmail.com) is a member of the Journal of Physical Activity and Health editorial board. practitioners) to inform policy development and program operation at the federal level. For instance, the head of each federal agency is required to include, as part of the agency's strategic plan, an assessment of the coverage, quality methods, effectiveness, and independence of the statistics, evaluation, research, and analysis efforts of the agency for identifying and addressing policy questions relevant to the programs, policies, and regulations of the agency (Act § 101(c)(3), 5 U.S.C. § 306(a)(9)). In addition, the agency head is required to consult with the public on the development of the agency's strategic plan (Act § 101(a)(2), 5 U.S.C. $\S 312$ (c)). Similarly, in developing a unified government-wide evidence-building plan, the Director of the Office of Management and Budget is required to establish an interagency Advisory Committee on Data for Evidence Building to review, analyze, and make recommendations on how to promote the use of federal data for evidence building (Act § 101(a)(2), 5 U.S.C. § 315(a)). The Advisory Committee must include representatives of state and local governments and nongovernmental stakeholders with expertise in government data policy, privacy, technology, transparency policy, evaluation and research methodologies, and other relevant subjects (Act § 101(a)(2), 5 U.S.C. § 315(b)(7)). Finally, on July 10, 2019, the Acting Director of the Office of Management and Budget issued a Memorandum for Heads of Executives Departments and Agencies, which provides the initial guidance for implementing the recently enacted "Evidence Act." Among other things, the guidance emphasizes the importance of engaging with external stakeholders on evidence-based policymaking issues. $^{4}$

The work of the Commission and the passage of the Act underscore the importance of evidence-based policymaking and clearly provide an avenue for the JPAH Community to advocate for effective health-promoting policy at the federal level. With their expertise concerning the importance of regular physical activity to human health and social function, each member of the JPAH Community is uniquely positioned to leverage the provisions of the Act in helping policymakers to interpret the science and make informed policy decisions. Moreover, although the content published in the JPAH does indeed constitute the type of sound evidence that should be informing policymakers, providing a face and a voice to that science (as is required by the Act) can go a long way toward fully informing healthy public policy.

\section{References}

1. Evidence-Based Policymaking Commission Act of 2016, Pub. L. No. 114-140. Stat. 317; 2016.

2. Commission on Evidence-Based Policymaking. The Promise of Evidence-Based Policymaking: Report of the Commission on Evidence-Based Policymaking. Washington, DC: Author; 2017. 
3. Foundations for Evidence-Based Policymaking Act of 2018, Pub. L. No. 115-435; 2019.

4. U.S. Office of Management and Budget. Memorandum For Heads of Executive Departments and Agencies: Phase I Implementation of the Foundations for Evidence-Based Policymaking Act of 2018: Learning Agendas, Personnel, and Planning Guidance. Washington, DC: Author; 2019. 